\title{
Electroless Deposition of Ferromagnetic Cobalt Nanoparticles in Propylene Glycol
}

\section{AUTHOR(S):}

Balela, Mary Donnabelle L.; Yagi, Shunsuke; Lockman, Zainovia; Aziz, Azizan; Amorsolo Jr., Alberto V.; Matsubara, Eiichiro

\section{CITATION:}

Balela, Mary Donnabelle L....[et al]. Electroless Deposition of Ferromagnetic Cobalt Nanoparticles in Propylene Glycol. JOURNAL OF THE ELECTROCHEMICAL SOCIETY 2009, 156(9): E139-E142

\section{ISSUE DATE:}

2009

URL:

http://hdl.handle.net/2433/109935

\section{RIGHT:}

(C) 2009 The Electrochemical Society 


\title{
Electroless Deposition of Ferromagnetic Cobalt Nanoparticles in Propylene Glycol
}

\author{
Mary Donnabelle L. Balela, ${ }^{\mathrm{a}, \mathrm{c}, \mathrm{z}}$ Shunsuke Yagi, ${ }^{\mathrm{a}, *}$ Zainovia Lockman, \\ Azizan Aziz, ${ }^{\text {b }}$ Alberto V. Amorsolo, Jr., ${ }^{\text {c }}$ and Eiichiro Matsubara ${ }^{\mathrm{a}}$ \\ ${ }^{a}$ Department of Materials Science and Engineering, Kyoto University, Kyoto 606-8501, Japan \\ ${ }^{b}$ School of Materials and Mineral Resources Engineering, Universiti Sains Malaysia, Nibong Tebal, \\ Penang 14300, Malaysia \\ ${ }^{c}$ Department of Mining, Metallurgical and Materials Engineering, University of the Philippines, Diliman, \\ Quezon City 1101, Philippines
}

\begin{abstract}
Ferromagnetic Co nanoparticles with diameters of about 40-400 nm are synthesized by electroless deposition in boiling propylene glycol. The Co particle size is decreased to a certain degree by varying the concentration of starting materials and by adding nucleating agents. The electrochemical behavior of propylene glycol is investigated by in situ measurements of mixed potential to understand the formation of Co nanoparticles in polyol systems. The mixed potential decreases with an increase in temperature and in the presence of $\mathrm{NaOH}$, which suggests the faster decomposition of propylene glycol. It also shifts abruptly to a more negative value when nucleating agents are added. This indicates that nucleating agents catalyze both the oxidation reaction of propylene glycol and the reduction reaction of Co(II) species, as well as aid in the formation of Co nanoparticles as heterogeneous nucleation sites.
\end{abstract}

(C) 2009 The Electrochemical Society. [DOI: 10.1149/1.3169776] All rights reserved.

Manuscript submitted May 12, 2009; revised manuscript received June 9, 2009. Published July 22, 2009.

The polyol synthesis, that is, the synthesis of metal nanoparticles by electroless deposition in polyol, has been extensively studied over the years. ${ }^{1-5}$ It is widely used due to its simplicity because polyol acts both as a solvent and as a reducing agent and in some cases also as a protective agent for agglomeration. In the polyol synthesis, the nucleation and growth of nanoparticles can be effectively separated by controlling the process parameters such as reaction temperature, concentration of starting materials, and addition of nucleating agents. ${ }^{2,4}$ Thus, metal nanoparticles with a very narrow size distribution can be produced. Metal nanoparticles, such as $\mathrm{Co},{ }^{4,6} \mathrm{Ni},{ }^{7} \mathrm{Fe}^{8}{ }^{8} \mathrm{Ag},{ }^{9} \mathrm{Pt},{ }^{10}$ and their alloys, ${ }^{3,5,11}$ have been synthesized by this method.

The overall reaction in the polyol synthesis consists of the reduction of metal species in solution and the simultaneous oxidation of polyols. Bonet et al. ${ }^{12}$ studied the electrochemical reduction of noble metals in ethylene glycol using platinum and glassy carbon rotating disk electrodes. They reported that ethylene glycol is electrochemically stable from -1.15 to $1.65 \mathrm{~V}$ vs saturated calomel electrode (SCE) on a glass carbon electrode, while it is stable from -0.82 to $2.0 \mathrm{~V}$ vs SCE on a Pt electrode at room temperature. We have applied in situ measurements of the mixed potential to discuss the thermodynamic driving force of $\mathrm{Cu}$ and $\mathrm{Ni}$ deposition with hydrazine as a reducing agent in both aqueous and nonaqueous solutions. ${ }^{13,14}$ In this paper, we present a formation of Co nanoparticles by electroless deposition in boiling propylene glycol. The effects of process parameters, such as precursor concentration and amounts of different nucleating agents on the morphology and size distribution, are also studied. The magnetic properties of the Co nanoparticles, i.e., saturation magnetization and coercivity, at room temperature are investigated. The electrochemical behavior of propylene glycol at high temperatures up to the boiling point is investigated by in situ measurements of the mixed potential in propylene glycol. The optimum condition for the deposition of Co nanoparticles is determined. Co nanoparticles are applicable to electronics, optics, magnetic recording, biomedicine, and catalysis. ${ }^{15-17}$

\section{Experimental}

$\mathrm{Co}$ (II) acetate tetrahydrate $\left[\mathrm{Co}\left(\mathrm{C}_{2} \mathrm{H}_{3} \mathrm{O}_{2}\right)_{2} \cdot 4 \mathrm{H}_{2} \mathrm{O}\right.$, British Drug House $(\mathrm{BDH})]$ was used as a $\mathrm{Co}(\mathrm{II})$ ionic source. Silver nitrate $\left(\mathrm{AgNO}_{3}\right.$, AllChem), palladium chloride $\left(\mathrm{PdCl}_{2}\right.$, Merck), and hexachloroplatinic acid hexahydrate $\left(\mathrm{H}_{2} \mathrm{PtCl}_{6} \cdot \mathrm{H}_{2} \mathrm{O}, \mathrm{BDH}\right)$ were used as nucleating agents. Propylene glycol $\left(\mathrm{C}_{3} \mathrm{H}_{8} \mathrm{O}_{2}\right.$, Universal

* Electrochemical Society Active Member

z E-mail: balela.m@hw8.ecs.kyoto-u.ac.jp
Laboratory \& Chemical Supplies) was used as a solvent, a reducing agent, and a dispersing agent. Sodium hydroxide $(\mathrm{NaOH}$, Systerm) was used to introduce $\mathrm{OH}^{-}$ions into the solutions.

A $0.1 \mathrm{M} \mathrm{Co}$ (II)-propylene glycol solution was prepared by dissolving $\mathrm{Co}$ (II) acetate tetrahydrate powder in a $0.25 \mathrm{M} \mathrm{NaOH}-$ propylene-glycol solution. For the addition of nucleating agents, 2.5 $\mathrm{mM} \mathrm{AgNO} 3, \mathrm{PdCl}_{2}$, and $\mathrm{H}_{2} \mathrm{PtCl}_{6} \cdot \mathrm{H}_{2} \mathrm{O}$ propylene glycol solutions were prepared. $0.1 \mathrm{M}$ lithium perchlorate $\left(\mathrm{LiClO}_{4}\right.$, Nacalai Tesque) was added into the solution as a supporting electrolyte only in the measurement of the mixed potential. The reaction solution was then stirred and heated to a boiling temperature of about $150-165^{\circ} \mathrm{C}$ for $2 \mathrm{~h}$. After the reaction, Co nanoparticles were separated by centrifugation and washed several times with ethanol and acetone before drying at room temperature in a vacuum.

The morphology of Co nanoparticles was observed by a transmission electron microscope (TEM, Philips, CM12) and a fieldemission-scanning electron microscope (Zeis Supra, 55VP). The mean diameter was determined by image analyses for 300 nanoparticles in each sample. The structure was analyzed by X-ray diffraction (XRD, Siemens, D500). Magnetic properties, such as saturation magnetization and coercivity, were measured at room temperature using a vibrating sample magnetometer (DMS, model 10) with a magnetic field of $2 \mathrm{~T}$. The mixed potential on a platinum $(\mathrm{Pt})$ plate with an active surface area $\left(360 \mathrm{~mm}^{2}\right)$ was measured by a potentiostat/galvanostat (Hokuto Denko Co. Ltd., HA-151), and the Pt plate was mechanically polished before every measurement. A $\mathrm{Ag} / \mathrm{AgCl}$ electrode (Horiba, 2565A-10T) immersed in a $3.33 \mathrm{M} \mathrm{KCl}$ aqueous solution was used as a reference electrode. The reference electrode was connected to the reaction solution through a glass bridge filled with the starting Co(II)-propylene glycol solution. In this paper, all potentials are reported against the potential of the $\mathrm{Ag} / \mathrm{AgCl}$ electrode $(0.206 \mathrm{~V}$ vs standard hydrogen electrode at $\left.25^{\circ} \mathrm{C}\right)$.

\section{Results and Discussion}

Electrochemical behavior of propylene glycol.-Figure 1 shows the change in mixed potentials with the reaction temperature up to the boiling point with and without $\mathrm{NaOH}$. Both mixed potentials decrease with an increase in temperature. In the absence of $\mathrm{NaOH}$ the mixed potential is about $0.1 \mathrm{~V}$ vs $\mathrm{Ag} / \mathrm{AgCl}$ at $50^{\circ} \mathrm{C}$ and shows the minimum value (about $-0.52 \mathrm{~V}$ vs $\mathrm{Ag} / \mathrm{AgCl}$ ) at the boiling temperature. Thus, the strongest reducing ability is achieved at the boiling point. The addition of $\mathrm{NaOH}$ shifts the mixed potential more negatively, as shown in Fig. 1. In the presence of $\mathrm{NaOH}$, the mixed potential is about $-0.35 \mathrm{~V}$ vs $\mathrm{Ag} / \mathrm{AgCl}$ at $50^{\circ} \mathrm{C}$. The minimum of the potential curve (about $-1.0 \mathrm{~V}$ vs $\mathrm{Ag} / \mathrm{AgCl}$ ) is reached at $130^{\circ} \mathrm{C}$, 


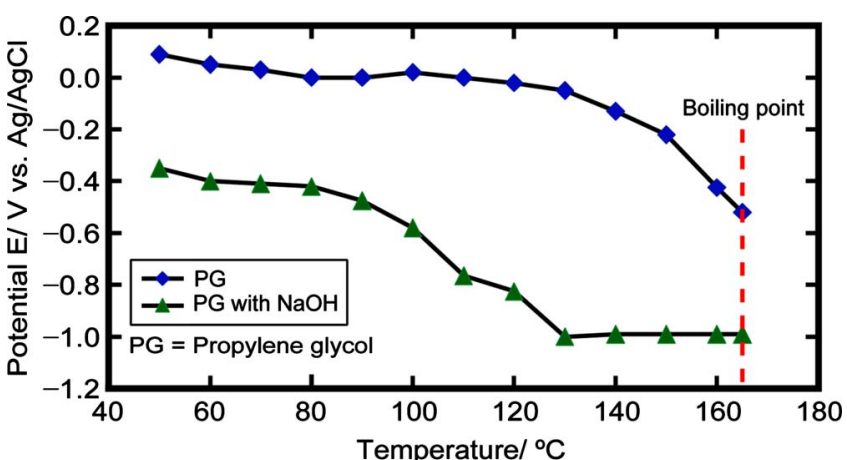

Figure 1. (Color online) Changes in mixed potential measured with temperatures up to the boiling point $\left(165^{\circ} \mathrm{C}\right)$ in propylene glycol with and without $0.25 \mathrm{M} \mathrm{NaOH}$

and the value remains constant up to the boiling point. The mixed potential drastically changes because the presence of $\mathrm{OH}^{-}$ions accelerates the decomposition of propylene glycol and the decomposition rate holds a balance to the evaporation rate above $130^{\circ} \mathrm{C}$.

Figure 2 shows the time dependence of the mixed potential in both solutions at the boiling point. In the absence of $\mathrm{NaOH}$, the mixed potential of propylene glycol is more positive than that in the presence of $\mathrm{NaOH}$, and it is variable as shown in Fig. 2a. This difference in the mixed potential can be related to the concentration of dehydrogenation products of propylene glycol, i.e., the decomposition products with strong reducing ability such as aldehyde. In the absence of $\mathrm{NaOH}$, the dehydrogenation of propylene glycol is slow, which leads to higher potentials. In contrast, the mixed potential of propylene glycol is almost constant and is much lower in the presence of $\mathrm{NaOH}$, suggesting a higher concentration of decomposition products in the solution. Without $\mathrm{NaOH}$, the potential shows no change during the first $10 \mathrm{~min}$ at the boiling temperature, and then gradually increases until it levels off after $1 \mathrm{~h}$. Because abundant decomposition products are formed when the temperature is increased to the boiling point, the mixed potential is initially stable. However, it is possible that evaporation of the decomposition products becomes faster than their formation at the boiling point, leading to a slight increase in the mixed potential with time. As the reaction continues, the dehydrogenation of propylene glycol and the evaporation of dehydrogenation products occur at comparable rates, leading to the stabilization of the mixed potential.

Formation of Co nanoparticles.- Figure 3 shows XRD patterns of Co nanoparticles of about 150-400 nm diameter formed without any nucleating agent. The diffraction peaks at $2 \theta=44.4,75.6$, and $92.5^{\circ}$ are attributed to both face-centered cubic (fcc) and hexagonal close-packed (hcp) Co. The fcc peaks at 51.6 and $98^{\circ}$ and two broad hcp peaks at 41 and $47.2^{\circ}$ are also observed. Thus, the synthesized

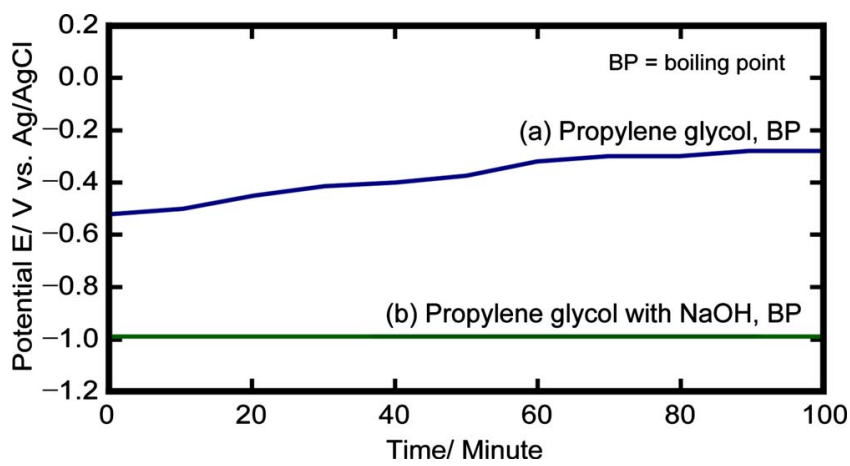

Figure 2. (Color online) Changes in mixed potential measured at the boiling point $\left(165^{\circ} \mathrm{C}\right)$ in (a) pure propylene glycol and (b) propylene glycol with $0.25 \mathrm{M} \mathrm{NaOH}$.

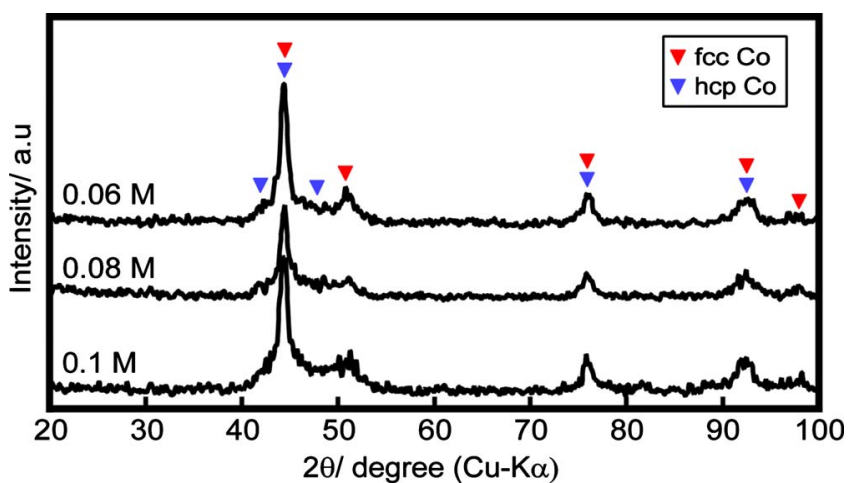

Figure 3. (Color online) XRD patterns of Co nanoparticles prepared by electroless deposition using (a) 0.06, (b) 0.08, and (c) $0.1 \mathrm{M} \mathrm{Co}$ (II) acetate tetrahydrate. The mean diameters of Co nanoparticles are (a) 388, (b) 364, and (c) $298 \mathrm{~nm} . \mathrm{NaOH}=0.25 \mathrm{M}$.

Co nanoparticles have both fcc and hcp structures, which agrees with reported results. ${ }^{4,6,8}$ No peaks of Co oxides and hydroxides are observed even at higher $\mathrm{Co}$ (II) acetate tetrahydrate concentrations, as shown in Fig. 3. This suggests that all Co(II) acetate tetrahydrate is reduced to Co nanoparticles by the present method even at high concentrations of a Co(II) precursor. Figure 4 shows the scanning electron microscopy (SEM) images of the Co nanoparticles without nucleating agents obtained from the solution with different concentrations of $\mathrm{Co}(\mathrm{II})$ acetate tetrahydrate. The average particle size decreases with an increase in the amount of $\mathrm{Co}$ (II) acetate tetrahydrate. A larger number of $\mathrm{Co}$ (II) ions are available at a time for Co nucleation with an increase in the concentration of $\mathrm{Co}(\mathrm{II})$ acetate tetrahydrate, which results in the formation of many nuclei at an early stage of the reaction. ${ }^{18,19}$ The relative standard deviation of the particle size is about $15 \%$ in all samples, suggesting sharp size distributions.

Effect of nucleating agent.- Figure 5 shows TEM images of the Co nanoparticles synthesized with and without nucleating agents. The addition of nucleating agents, such as $\mathrm{AgNO}_{3}, \mathrm{PdCl}_{2}$, and $\mathrm{H}_{2} \mathrm{PtCl}_{6} \cdot 6 \mathrm{H}_{2} \mathrm{O}$, significantly reduces the size of Co particles. The mean size of Co nanoparticles is plotted to the concentration ratio of $[\mathrm{X}] /[\mathrm{Co}(\mathrm{II})]$, where $\mathrm{X}=\mathrm{Ag}(\mathrm{I}), \mathrm{Pd}(\mathrm{II})$, and $\mathrm{Pt}(\mathrm{IV})$ in Fig. 6. Smaller Co nanoparticles are essentially synthesized with a larger amount of nucleating agent. The nucleating agents apparently work as heterogeneous nucleation sites. Submicrometer-sized particles (100-400 nm) are only synthesized with $\mathrm{AgNO}_{3}$, and the smallest Co nanoparticles of $106 \mathrm{~nm}$ diameter are obtained at a concentration ratio of $2.5 \times 10^{-2}$. Beyond this concentration ratio, agglomerated particles are obtained. In contrast, particles of 40-120 nm are prepared with $\mathrm{PdCl}_{2}$ and $\mathrm{H}_{2} \mathrm{PtCl}_{6} \cdot 6 \mathrm{H}_{2} \mathrm{O}$. Pt salts with relatively high solubility in propylene glycol produce extremely fine particles, which seem to act as stable Pt nuclei. ${ }^{20}$ In $\mathrm{AgNO}_{3}, \mathrm{Ag}$ particles are easily agglomerated at elevated temperatures. ${ }^{9,20}$ Thus, the Ag particles do not effectively work as the nuclei of Co particles. Similar results have been previously reported by Viau et al., ${ }^{20}$ who synthesized $\mathrm{Co}_{80} \mathrm{Ni}_{20}$ particles in ethylene glycol using $\mathrm{AgNO}_{3}$ and $\mathrm{K}_{2} \mathrm{PtCl}_{4}$.

Figure 7 shows the changes in mixed potentials in the $\mathrm{Co}(\mathrm{II})$ propylene glycol suspensions with and without a nucleating agent ( $2.5 \mathrm{mM} \mathrm{H} \mathrm{H}_{2} \mathrm{PtCl}_{6} \cdot 6 \mathrm{H}_{2} \mathrm{O}$ ). In both cases, the mixed potential is around $-0.35 \mathrm{~V}$ vs $\mathrm{Ag} / \mathrm{AgCl}$ at $50^{\circ} \mathrm{C}$, which is close to the value obtained for propylene glycol containing $\mathrm{NaOH}$ in Fig. 1. With an increase in temperature, the mixed potential gradually decreases until the potential reaches about $-0.9 \mathrm{~V}$ vs $\mathrm{Ag} / \mathrm{AgCl}$. For the $\mathrm{Co}$ particles synthesized without any nucleating agent, the minimum mixed potential is $-1.0 \mathrm{~V}$ vs $\mathrm{Ag} / \mathrm{AgCl}$ at about $150^{\circ} \mathrm{C}$. The potential remains almost constant at around $-0.9 \mathrm{~V}$ vs $\mathrm{Ag} / \mathrm{AgCl}$ over $150^{\circ} \mathrm{C}$ up to the higher $165^{\circ} \mathrm{C}$ limit of the boiling point. The color of the reaction suspension changes from pink to black at the boiling point, indicating that the reduction of $\mathrm{Co}(\mathrm{II})$ species starts near the 
(a)

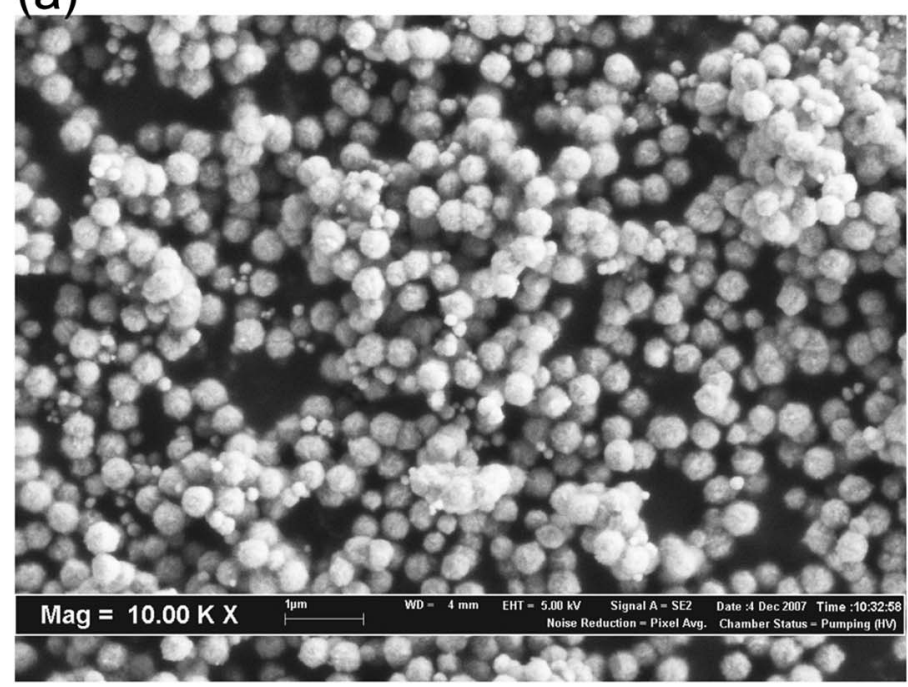

(c)

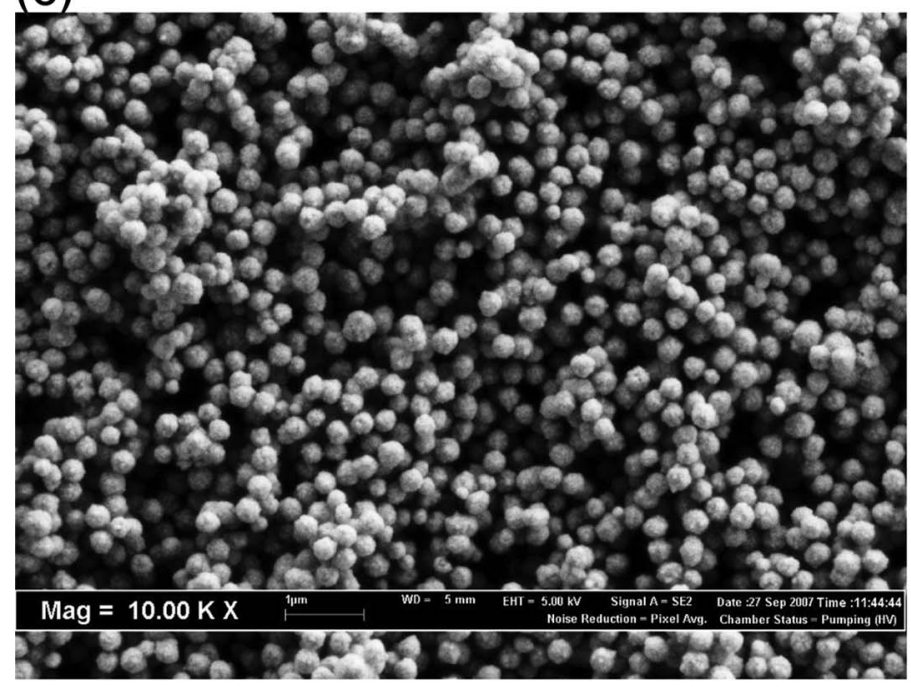

(b)

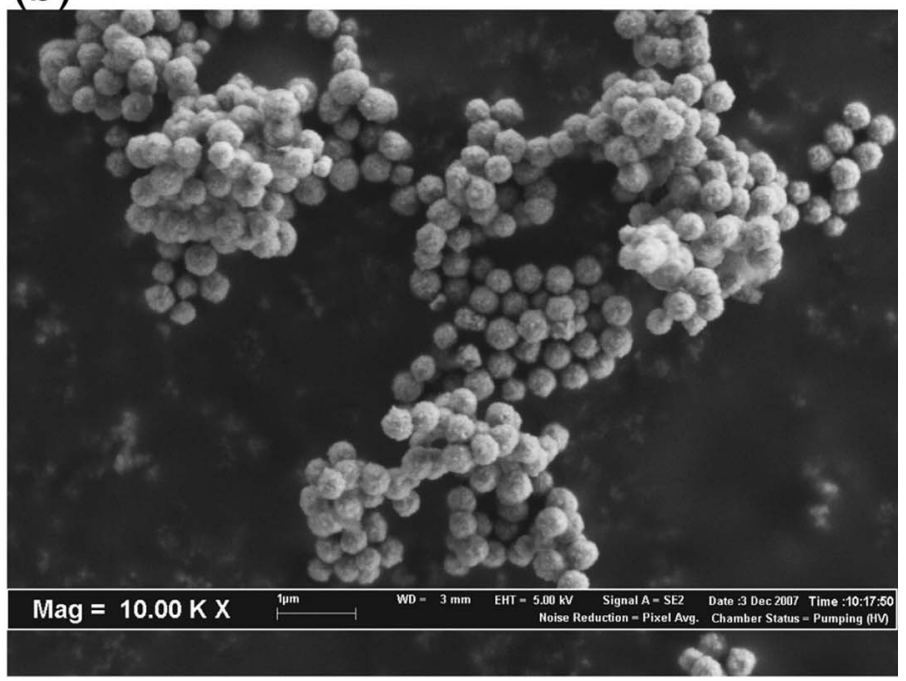

(d)

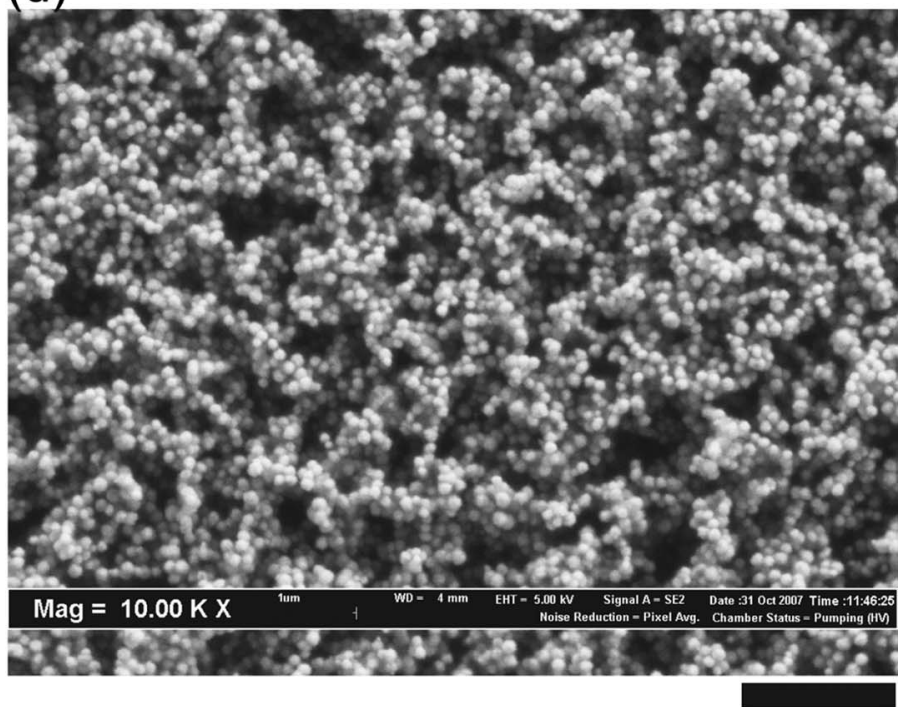

$1 \mu \mathrm{m}$

Figure 4. SEM images of Co nanoparticles prepared by electroless deposition using (a) 0.06, (b) 0.08 , (c) 0.1 , and (d) 0.12 M Co(II) acetate tetrahydrate. The mean diameters of Co nanoparticles are (a) 388, (b) 364, (c) 298 , and (d) $152 \mathrm{~nm}$. NaOH $=0.25 \mathrm{M}$.

boiling point. In the presence of $\mathrm{H}_{2} \mathrm{PtCl}_{6} \cdot 6 \mathrm{H}_{2} \mathrm{O}$, the minimum mixed potential is about $-0.9 \mathrm{~V}$ vs $\mathrm{Ag} / \mathrm{AgCl}$ at $120^{\circ} \mathrm{C}$. The potential does not change significantly until the temperature becomes the boiling point. The mixed potential is a much larger negative value in the presence of the nucleating agent, which indicates that the decomposition of propylene glycol and the reduction of Co(II) species can occur at lower temperatures. The potential reaches the minimum at a lower temperature with the nucleating agent. Consequently, the presence of $\mathrm{H}_{2} \mathrm{PtCl}_{6} \cdot 6 \mathrm{H}_{2} \mathrm{O}$ not only supplies the nucleation sites for Co nanoparticles, but also accelerates the redox reaction.

Room-temperature magnetic properties of cobalt particles. - Figure 8 shows the changes in the coercivity of the Co particles with respect to the mean particle size. The maximum coercivity of 560 Oe is achieved by the Co particles with an average size of $61 \mathrm{~nm}$. The coercivity of the particles larger than $61 \mathrm{~nm}$ decreases with the increase in particle size, whereas the coercivity of the Co particles smaller than $61 \mathrm{~nm}$ in mean diameter decreases with the decrease in particle size. This clearly suggests two mechanisms of magnetization reversal. ${ }^{5,21}$ The larger particles exhibit multidomain behavior
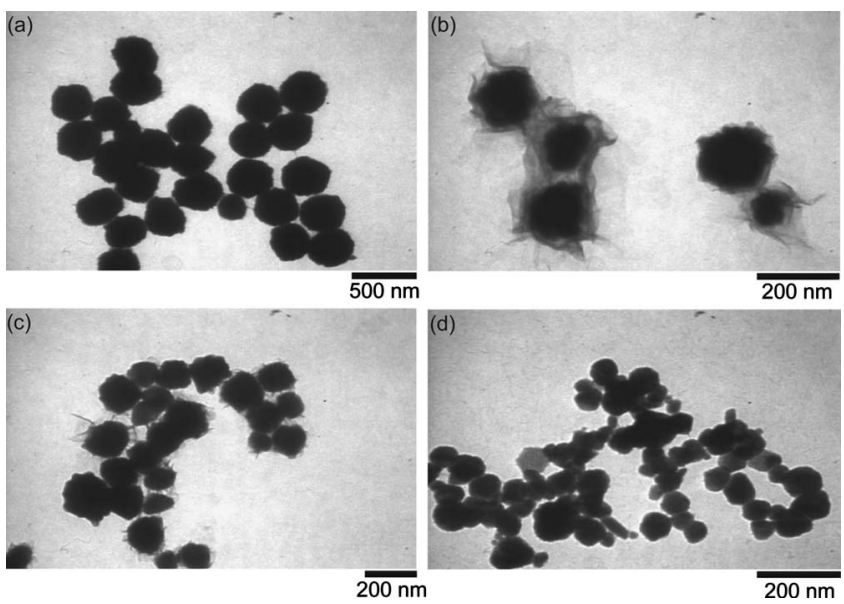

Figure 5. TEM images of Co nanoparticles prepared (a) without any nucleating agent and by nucleating with $2.5 \mathrm{mM}$ (b) $\mathrm{AgNO}_{3}$, (c) $\mathrm{PdCl}_{2}$, and (d) $\mathrm{H}_{2} \mathrm{PtCl}_{6} \cdot 6 \mathrm{H}_{2} \mathrm{O}$. The mean diameters of Co nanoparticles are (a) 298 , (b) 106 (c) 121, and (d) $61 \mathrm{~nm}$. Co(II) acetate tetrahydrate $=0.1 \mathrm{M} ; \mathrm{NaOH}$ $=0.25 \mathrm{M}$. 


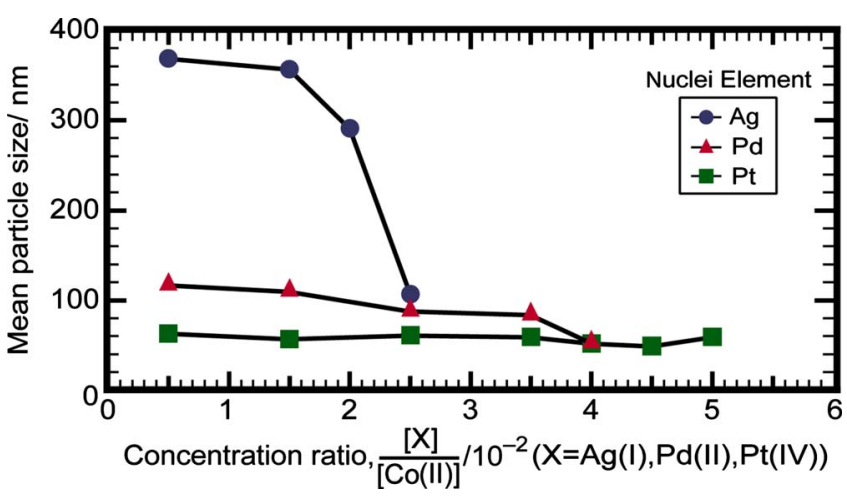

Figure 6. (Color online) Changes in the mean particle size of the Co nanoparticles with increasing amounts of nucleating agents $\left(\mathrm{AgNO}_{3}, \mathrm{PdCl}_{2}\right.$, and $\left.\mathrm{H}_{2} \mathrm{PtCl}_{6} \cdot 6 \mathrm{H}_{2} \mathrm{O}\right) . \mathrm{Co}(\mathrm{II})$ acetate tetrahydrate $=0.1 \mathrm{M} ; \mathrm{NaOH}=0.25 \mathrm{M}$.

where magnetization reversal is achieved by domain wall motion. ${ }^{5,21}$ This is also supported by the linear relationship between coercivity and the inverse of the mean particle size, ${ }^{21}$ as shown in the inset of Fig. 8. In contrast, the smaller particles show single-domain properties where magnetization reversal is accomplished by coherent spin rotation. ${ }^{5,21}$ The decline of the coercivity with the decrease in particle size is due to thermal effects. ${ }^{22,23}$

The largest saturation magnetization is about $168 \mathrm{emu} \mathrm{g}^{-1}$, which is achieved by the largest Co particles, $364 \mathrm{~nm}$ in diameter. This value is close to the saturation magnetization for bulk hep Co $\left(\sim 166 \mathrm{emu} \mathrm{g}^{-1}\right),{ }^{21,23,24}$ indicating that $364 \mathrm{~nm}$ diameter Co particles show bulk magnetic properties.

\section{Conclusions}

We have investigated the electroless deposition of Co particles in boiling propylene glycol by in situ measurements of the mixed potential. The mixed potential of propylene glycol decreases with an increase temperature and with the addition of $\mathrm{NaOH}$. The decrease in mixed potential implies a stronger reducing ability for propylene glycol due to the formation of decomposition products such as aldehyde. The mean diameter of the Co particles is varied to some extent by changing the concentration of the starting material and by the addition of nucleating agents. The presence of nucleating agents aids in the formation of Co particles with sharp size distributions and enhances the rate of the redox reaction because the mixed potential is lowered and the reduction of Co(II) species occurs at a temperature below the boiling point. The Co nanoparticles are ferromagnetic at room temperature, and the largest coercivity of about 560 Oe is measured on the Co nanoparticles of $61 \mathrm{~nm}$ mean diameter.

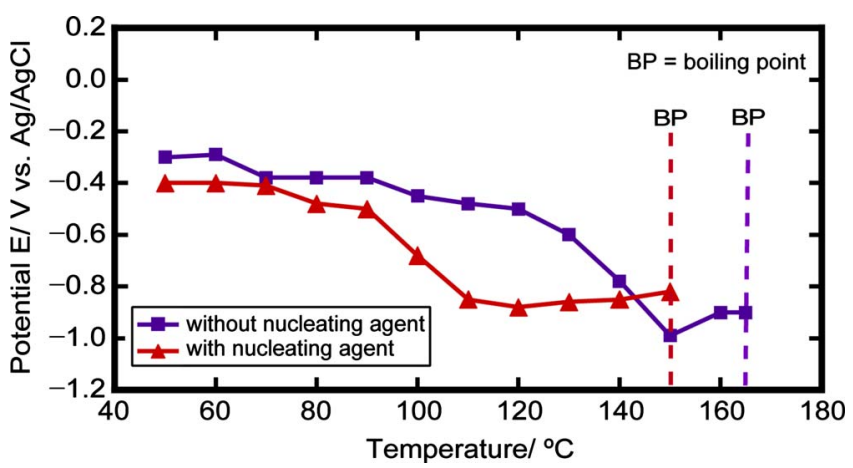

Figure 7. (Color online) Changes in mixed potential measured during the reduction of $\mathrm{Co}$ (II) species in propylene glycol with and without $2.5 \mathrm{mM}$ $\mathrm{H}_{2} \mathrm{PtCl}_{6} \cdot 6 \mathrm{H}_{2} \mathrm{O}$. $\mathrm{Co}(\mathrm{II})$ acetate tetrahydrate $=0.1 \mathrm{M} ; \mathrm{NaOH}=0.25 \mathrm{M}$.

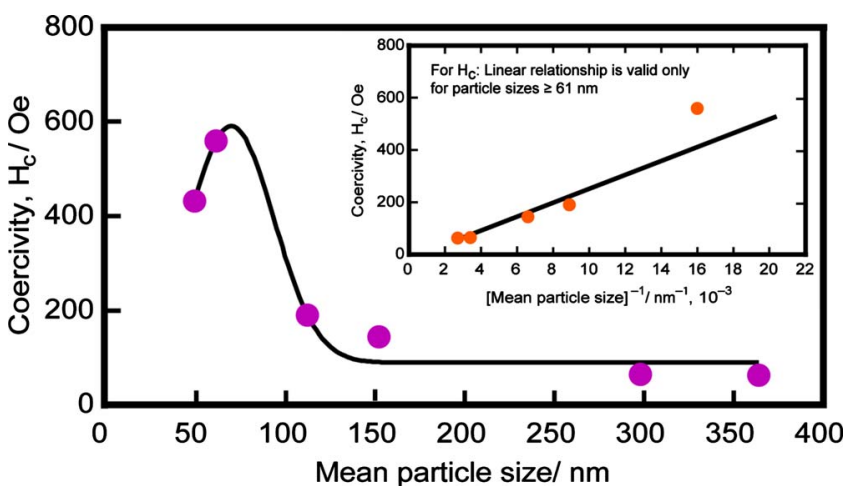

Figure 8. (Color online) Coercivity $\left[H_{\mathrm{c}}(\mathrm{Oe})\right]$ at room temperature plotted vs the mean particle size of Co nanoparticles. Inset shows the linear relationship of the coercivity $\left[H_{\mathrm{c}}(\mathrm{Oe})\right]$ vs the inverse of the mean particle size of the Co nanoparticles with diameters of $\geq 61 \mathrm{~nm}$.

\section{Acknowledgments}

The authors express their gratitude to Makoto Kawamori and Hidetaka Nakanishi for their assistance and advice in various aspects of this research. This research was supported by a grant-in-aid for Knowledge Cluster Initiative (Kyoto Nanotechnology Cluster), a grant-in-aid for the Global COE Program (International Center for Integrated Research and Advanced Education in Materials Science), and a grant-in-aid for Young Scientists (B20760505), all from the Japan Society for the Promotion of Science, Ministry of Education, Culture, Sports, Science and Technology of Japan. This research was also supported by the Kurata Memorial Hitachi Science and Technology Foundation and the Shorai Foundation for Science and Technology.

Kyoto University assisted in meeting the publication costs of this article.

\section{References}

1. F. Fiévet, F. Fiévet-Vincent, J.-P. Lagler, B. Dumont, and M. Figlarz, J. Mater. Chem., 3, 627 (1993)

2. G. Viau, F. Fiévet-Vincent, and F. Fiévet, Solid State Ionics, 84, 259 (1996).

3. P. Toneguzzo, G. Viau, O. Archer, E. Guillet, E. Bruneton, F. Fiévet-Vincent, and F. Fiévet, J. Mater. Sci., 35, 3767 (2000).

4. T. Hinotsu, B. Jeyadevan, C. N. Chinnasamy, K. Shinoda, and K. Tohji, J. Appl. Phys., 95, 7477 (2004).

5. C. Luna, M. Morales, C. J. Serna, and M. Vazquez, Nanotechnology, 15, S293 (2004).

6. N. Chakroune, G. Viau, C. Ricolleau, F. Fiévet-Vincent, and F. Fiévet, J. Mater. Chem., 13, 312 (2003).

7. M. S. Hegde, D. Larcher, L. Dupont, B. Beaudoin, K. Tekaia-Elhsissen, and J.-M. Tarascon, Solid State Ionics, 93, 33 (1997).

8. G. Viau, F. Fiévet-Vincent, and F. Fiévet, J. Mater. Chem., 6, 1047 (1996).

9. P.-Y. Silvert, R. Herrera-Urbina, and K. Tekaia-Elhsissen, J. Mater. Chem., 7, 293 (1997).

10. F. Bonet, K. Tekaia-Elhsissen, and K. Vijaya Sarathy, Bull. Mater. Sci., 23, 165 (2000)

11. C. N. Chinnasamy, B. Jeyadevan, K. Shinoda, and K. Tohji, J. Appl. Phys., 93, 7583 (2003).

12. F. Bonet, C. Guéry, D. Guyomard, R. Herrera Urbina, K. Tekaia-Elhsissen, and J.-M. Tarascon, Solid State Ionics, 126, 337 (1999).

13. S. Yagi, H. Nakanishi, E. Matsubara, S. Matsubara, T. Ichitsubo, K. Hosoya, and Y. Matsuba, J. Electrochem. Soc., 155, D474 (2008).

14. S. Yagi, T. Koyanagi, H. Nakanishi, T. Ichitsubo, and E. Matsubara, J. Electrochem. Soc., 155, D583 (2008).

15. S. Sun and C. B. Murray, J. Appl. Phys., 85, 4325 (1999).

16. T. Hyeon, Chem. Commun. (Cambridge), 10, 927 (2002).

17. Y. K. Su, C. M. Shen, T. Z. Yang, H. T. Yang, H. J. Gao, and H. L. Li, Appl. Phys. A: Mater. Sci. Process., 81, 569 (2005).

18. T. Sugimoto, Monodispersed Particles, pp. 368-377, Elsevier, Amsterdam (2001).

19. G. Cao, Nanostructures and Nanomaterials: Synthesis, Properties, and Applications, pp. 34-40, Imperial College, London (2004).

20. G. Viau, P. Toneguzzo, A. Pierrard, O. Archer, F. Fiévet-Vincent, and F. Fiévet, $S c r$ Mater, 44, 2263 (2001)

21. B. D. Cullity, Introduction to Magnetic Materials, pp. 400-523, Addison-Wesley, London (1972).

22. R. H. Kodama, J. Magn. Magn. Mater, 200, 359 (1999).

23. X. Batlle and A. Labarta, J. Phys. D: Appl. Phys., 35, R15 (2002)

24. D. L. Leslie-Pelecky, Chem. Mater, 8, 1770 (1996). 